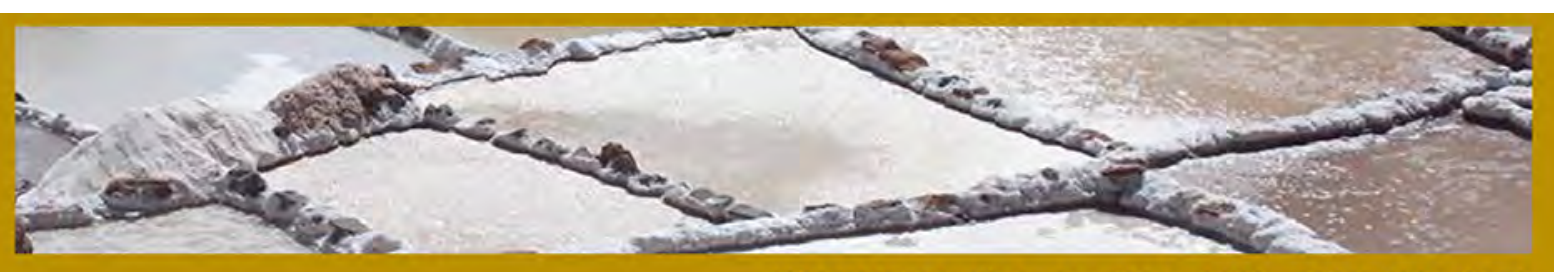

\title{
A RELAÇÃO DA ARTE COM OS ADOLESCENTES EM CONFLITO COM A LEI: UMA PESQUISA-AÇÃO NO MUNICIPIO DE CASCAVEL-PR
}

\author{
THE RELATION OF THE ART AND THE ADOLESCENTS IN CONFLICT \\ WITH THE LAW: A ACTION RESEARCH IN THE CITY OF CASCAVEL-PR
}

DOI: http://dx.doi.org/10.5965/1984317814012018108

Higor Antonio da Cunha, Rejane Ruaro eTânia Cristina Kaminski Alves Assini - Faculdade de Ciências Sociais Aplicadas de Cascavel

\begin{abstract}
RESUMO: A arte cria chances de integração social, proporciona afirmação pessoal e enfrenta o desafio da reconstrução de um projeto de vida. Ela também proporciona a expressão e comunicação, trazendo reflexões tanto ao artista quanto ao contemplador. Considerando esse pressuposto, este artigo tem como objetivo investigar se a arte pode contribuir para a ressocialização de adolescentes em conflito com a lei. Por meio de pesquisas bibliográfica e documental sobre a execução de medidas socioeducativas, foram gerados dados e questionamentos relevantes aos aspectos em que a arte atua. Além disso, por meio de uma oficina de modelagem em argila, se averiguou a aplicabilidade da arte como instrumento neste processo supramencionado. Foi observado, nesta pesquisa-ação, que em alguns pontos a arte contribui para a reintegração destes sujeitos à sociedade e também desperta a autorreflexão. A partir dos resultados, é possível concluir que a arte tem força de intervir positivamente no plano de autoimagem e da autoestima, auxiliando o adolescente a buscar seu desenvolvimento como pessoa e como cidadão.
\end{abstract}

Palavras-chave: Arte; Pesquisa-ação; Ressocialização.

\begin{abstract}
Art creates opportunities for social integration, personal affirmation, and faces the challenge of rebuilding a life project. It also provides a form of expression and communication, bringing reflections to both the artist and the viewer. With this in mind, this article aims to investigate if art can contribute to a re-socialization of adolescents in conflict with the law. Through a bibliographical research and documentary research about the execution of socio-educational measures, data were generated and questions about the way art works. Besides, through a clay modeling workshop, was verified the application of the art as instrument in the process mentioned above. It was observed in that action research, that in some points art contributes to the reintegration of subjects in society and also to their self-reflection. From the results, it is possible to conclude that art has the power to intervene positively in the plane of self-image and self-esteem, helping the adolescent to seek its development as a person and as a citizen.
\end{abstract}

Keywords: Art; Action research; Resocialization; 


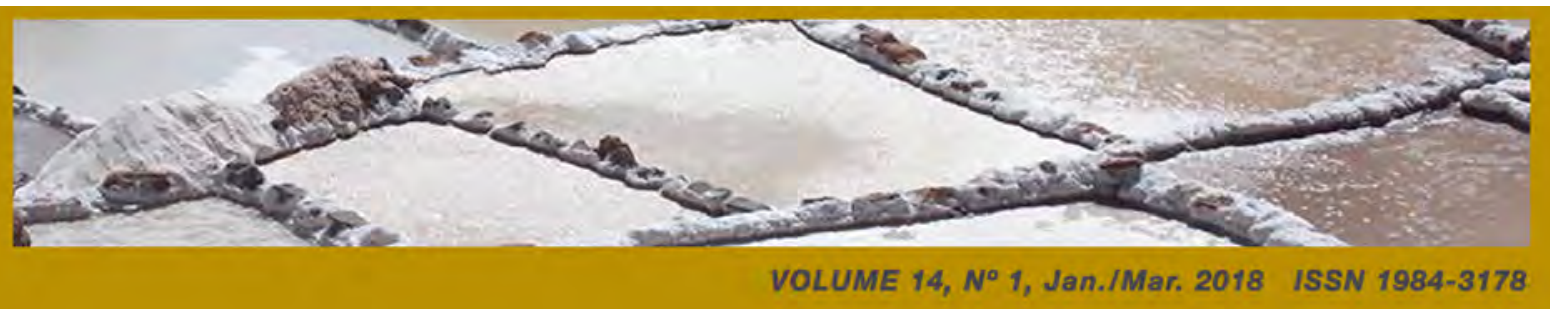

\section{INTRODUÇÃO}

Ao longo da história, a arte tem ganhado várias definições e finalidades. Diversas teorias surgiram a fim de justificar a existência do fazer artístico. Conforme o historiador Gombrich (1999) teoriza, primeiramente, a arte tinha função mágica, ao fazer parte do ritual de caça dos homens das cavernas. Com o passar do tempo, a técnica foi desenvolvendo-se, e com isso, a arte ganhou a função de representar a natureza de maneira realista. Entretanto, essa função unicamente de imitar a natureza foi superada, de maneira forte no fim do século XIX, para dar à arte um papel mais significativo, transformador. O potencial da arte passa a ser explorado para representar causas sociais e também expressar os sentimentos dos seres humanos, principalmente dos artistas. Ela assume a função de agente de transformação social, dando voz às minorias, ao trazer à tona as mazelas sociais e colocá-las em discussão no contexto das espacialidades locais.

Podemos colocar a questão da seguinte maneira: toda arte é condicionada pelo seu tempo e representa a humanidade em consonância com as ideias e aspirações, as necessidades e as esperanças de uma situação histórica particular (FISCHER, 2007, p.17).

Ao dar vazão à expressividade do artista, subjetivando emoções, a arte então, se torna um meio de expressão, no qual o artista pode extravasar impulsos, portanto, atuando como uma terapia. A arte, há algum tempo, tem ganhado um espaço importante na educação em suas várias modalidades, desde a Educação Infantil até a Educação de Jovens e Adultos. Já é consideravelmente usada em sanatórios para testes e inclusive auxiliando no tratamento de problemas psicológicos e psicossociais.

Cassirer (1971) reflete sobre os deslocamentos da arte:

É a vida dinâmica das formas artísticas — plásticas, musicais e poéticas que articulam as cores, as linhas, os ritmos, as palavras, em conjuntos significativos, que não apenas 'traduzem' os sentimentos do artista, mas lhes conferem uma existência palpável e objetiva [...]. (CASSIRER, 1971 apud NUNES, 2010, p. 70). 


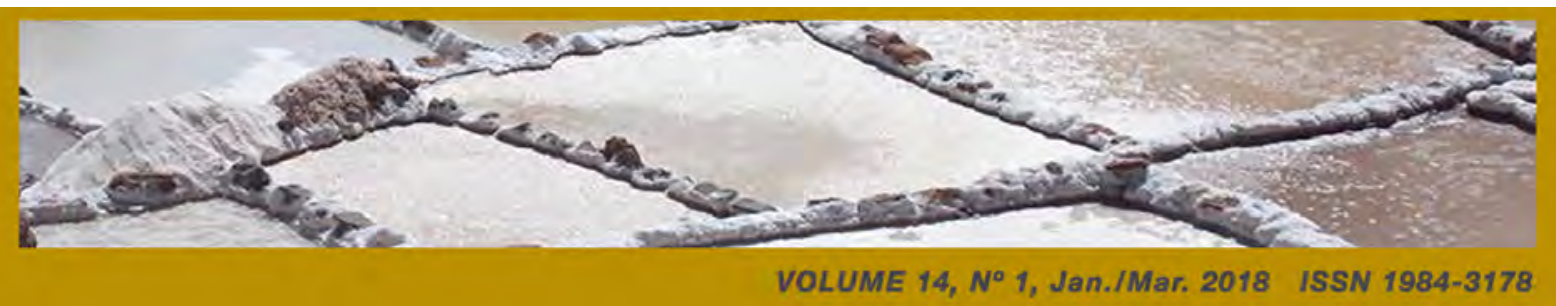

Considerando este potencial de deslocamento, o fazer artístico poderia servir também como instrumento para contribuir no processo de ressocialização de adolescentes em conflito com a lei? Propõe-se refletir sobre esta questão, neste texto, considerando resultados de pesquisa realizada com adolescentes entre 12 e 18 anos, que cumprem medida socioeducativa no Centro de Referência Especializado de Assistência Social - CREAS II no município de Cascavel - PR. Os dados coletados foram tratados por meio de referenciais teóricos de base em Ernst Fischer, Benedito Nunes e Michel Foucault.

\title{
2 SOBRE OS ADOLESCENTES EM CONFLITO COM A LEI
}

A adolescência é um período conturbado e confuso na mente do jovem, quando o adolescente tem o seu desenvolvimento psicológico e social até atingir a fase adulta, passando por questionamentos e transtornos inerentes a esse momento próprio da sua vida, dentre os quais, encontram-se os conflitos de personalidade, as mudanças na sua química cerebral, entre outros. Sobre esta fase do desenvolvimento humano, Aberastury (1981, p. 89-90) afirma:

\begin{abstract}
A tendência que caracteriza esta etapa [a adolescência] é, do ponto de vista do indivíduo, a necessidade do jovem de começar a fazer parte do mundo do adulto, e os conflitos que surgem têm a sua raiz nas dificuldades para ingressar nesse mundo e nas dificuldades do adulto para dar passagem a essa nova geração que lhe imporá uma revisão crítica de suas conquistas e do seu mundo de valores. [...] A característica da adolescência é que a criança, queira ou não, vê-se obrigada a entrar no mundo do adulto; e poderíamos dizer que primeiro entra através do crescimento e das mudanças do seu corpo e, muito mais tarde, através de suas capacidades e de seus afetos. [...] É por isso que outro dos problemas centrais do adolescente é a busca de sua identidade.
\end{abstract}

Ao pensarmos em adolescentes em conflito com a lei, devemos considerar a realidade social na qual estão inseridos. Muitas vezes, são crianças que, sem perspectiva de vida e aquém de qualquer oportunidade, não veem outra saída que não seja o crime.

Em junho de 2015, uma pesquisa realizada pelo Instituto de Pesquisa Econômica Aplicada (IPEA) mostrou dados dos jovens e adolescentes autores de ato infracional no 


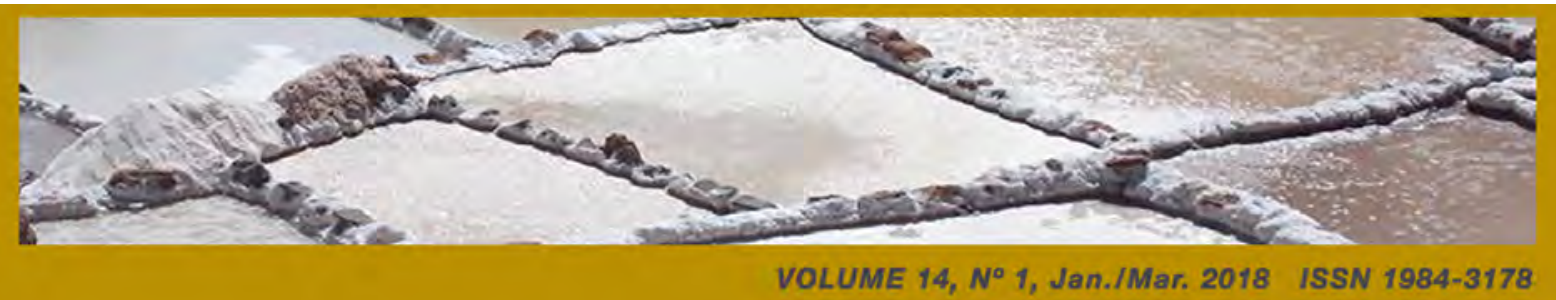

Brasil. Esta pesquisa, buscou contextualizar e esclarecer as realidades em que estão inseridos estes adolescentes em conflito com a lei, para nortear os debates sobre a maioridade penal que ganharam a mídia na época (SILVA; OLIVEIRA, 2015). Percebemos, por meio dos dados desta pesquisa que a cerca de $60 \%$ (sessenta por cento) destes infratores que respondem a medidas socioeducativas são negros, $51 \%$ (cinquenta e um por cento) não frequentava a escola e $66 \%$ (sessenta e seis por cento) vem de família pobre, cujo rendimento mensal varia entre menos de um a dois salários mínimos.

Eles sofrem pela desigualdade e preconceito que se perpetuam desde muito tempo. Quanto às infrações, a pesquisa aponta que menos de 10\% (dez por cento) destes menores cometem um crime de homicídio ou latrocínio, grande parte é presa por roubo e tráfico de drogas. No delito, eles encontram uma maneira de ajudar suas famílias, envolvendo-se com a marginalidade para ganhar dinheiro e tentar alcançar uma realidade diferente.

\section{ASPECTOS LEGAIS RELACIONADOS AOS ADOLESCENTES EM CONFLITO COM A LEI}

A Constituição Federal de 1988 estabelece a condição de inimputável do menor, exigindo a criação de lei específica a fim de regularizar tal situação. A lei específica criada foi a Lei $n^{\circ} 8.069 / 90$, que dá origem ao Estatuto da Criança e do Adolescente (ECA), o qual prevê vários direitos conferidos ao menor, por se encontrar em fase especial de desenvolvimento, necessitando, portanto, da proteção do Estado.

A partir daí os princípios fundamentais do ECA afirmam que crianças e adolescentes são prioridade absoluta. A prioridade absoluta engloba a primazia de receber proteção e socorro em todas as circunstâncias, a precedência do atendimento nos serviços públicos ou de relevância pública, a preferência na criação e execução das políticas sociais públicas e a destinação privilegiada de recursos públicos nas áreas relacionadas à proteção da infância e da juventude.

O ECA preconiza condições dignas de vida a todos, prevendo os direitos fundamentais da criança e adolescente. Todos esses direitos são baseados no caput do artigo $4^{\circ}$ da referida Lei: 
É dever da família, da comunidade, da sociedade em geral e do poder público assegurar, com absoluta prioridade, a efetivação dos direitos referentes a vida, a saúde, a alimentação, a educação, ao esporte, ao lazer, a profissionalização, a cultura, a dignidade, ao respeito, a liberdade e a convivência familiar e comunitária.

(BRASIL, 1990).

O ECA também serviu como base para esta pesquisa, uma vez que traz artigos relevantes para a aplicação da arte como base na ressocialização do adolescente. O Estatuto representa um consenso social, uma Lei de garantia de direitos que, acima de tudo, assegura os preceitos de igualdade e justiça social. Ele também expressa um projeto societário que considera a criança e o adolescente como sujeitos sociais de direitos e, consequentemente, de deveres pelo exercício desses direitos, tendo como base o artigo $3^{\circ}$ :

Art. $3^{\circ} \mathrm{A}$ criança e o adolescente gozam de todos os direitos fundamentais inerentes a pessoa humana, sem prejuízo da proteção integral de que trata esta lei, assegurando-se lhes, por lei ou por outros meios, todas as oportunidades e facilidades, a fim de lhes facultar o desenvolvimento físico, mental, moral, espiritual e social, em condições de liberdade e de dignidade.

((BRASIL, 1990).

$\mathrm{O}$ artigo $3^{\circ}$ supratranscrito é a base para a utilização da educação não formal como objeto de cumprimento de medida sócio educativa, pois prevê a formação física, mental, espiritual e social em condições de liberdade e dignidade. Desta forma, a educação não formal pode colaborar com essas formações necessárias a todo adolescente e não apenas cumprir uma ordem judicial que é a medida imposta.

O adolescente autor de ato infracional é sujeito de direitos e deveres. Assim, segundo o ECA, ele tem responsabilizações diante de seus atos. Estas responsabilizações são previstas no artigo 112 do Estatuto, abaixo transcritas: 


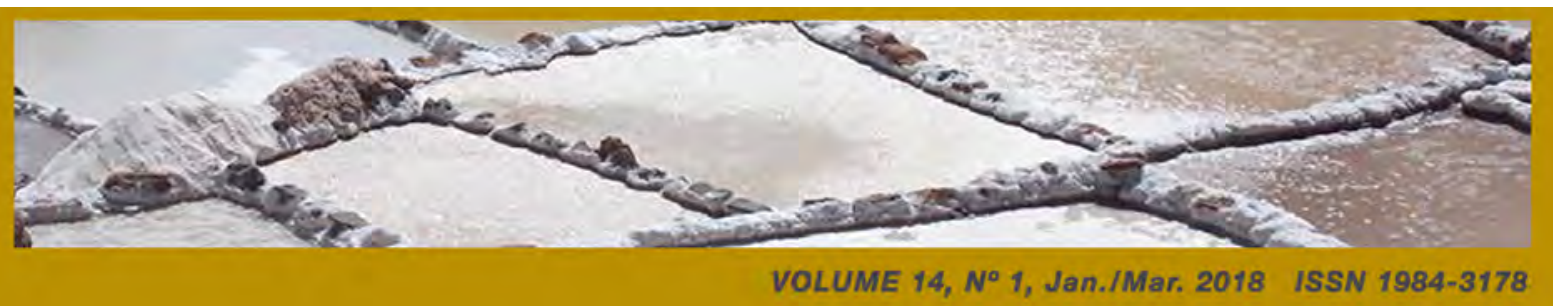

Art. 112. Verificada a prática de ato infracional, a autoridade competente poderá aplicar ao adolescente as seguintes medidas:

I- advertência;

II-obrigação de reparar o dano;

III-prestação de serviço à comunidade;

IV-liberdade assistida;

V-inserção de regime de semiliberdade;

VI-internação em estabelecimento educacional; [...]

(BRASIL, 1990).

Mediante o julgamento previsto em lei, respeitando-se os direitos nele existentes, o adolescente é informado pela autoridade competente sobre qual medida lhe será aplicada. Em casos mais graves, o adolescente é encaminhado aos Centro de Socioeducação - CENSE, onde cumprirá pena em regime de semiliberdade. Em infrações mais leves, usualmente, aplica-se a medida de prestação de serviço à comunidade que é cumprida vinculada ao CREAS. O cumprimento dessa medida tem como base o artigo 117 do ECA:

Art. 117. A prestação de serviços comunitários consiste na realização de tarefas gratuitas de interesse geral, por período não excedente a seis meses, junto a entidades assistenciais, hospitais, escolas, e outro estabelecimentos congêneres, bem como em programas comunitários ou governamentais.

Parágrafo único: As tarefas serão atribuídas conforme as aptidões do adolescente, devendo ser cumprida durante jornada máxima de oito horas semanais, aos sábados, domingos e feriados ou em dias uteis, de modo a não prejudicar a frequência à escola ou a jornada normal de trabalho. (BRASIL, 1990).

Com base nos artigos do ECA apontados acima, pode-se observar a importância da utilização da educação não formal para o cumprimento da medida sócio educativa. As tarefas atribuídas aos adolescentes devem ser voltadas à comunidade. Desta forma, existe uma responsabilização e ao mesmo tempo uma forma de mostrar ao jovem que as consequências de seus atos devem ser refletidas. 


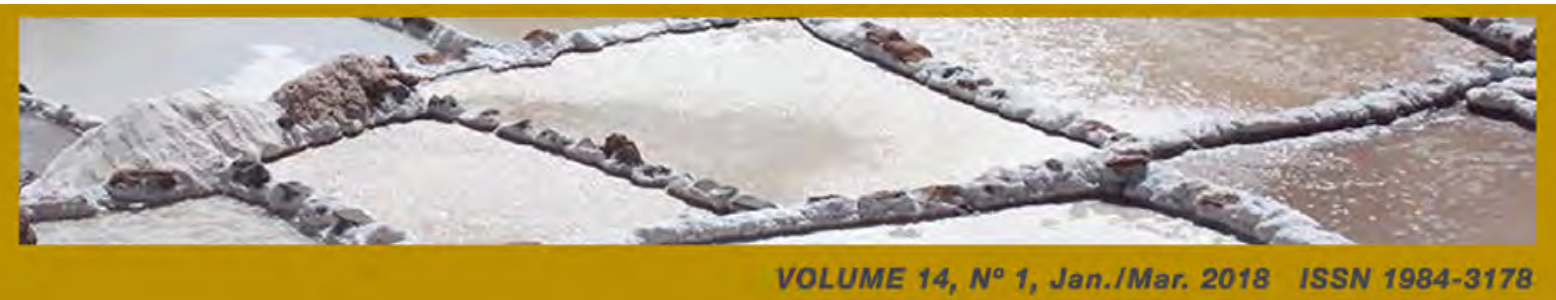

Conforme a mesma Lei, o adolescente que cumpre medida em liberdade tem seus direitos garantidos pelos artigos 15 ao 18 , que dispõem que o direito à liberdade e a dignidade da pessoa humana, em processo de desenvolvimento e como sujeito de direitos civis, devem ser garantidos. O respeito consiste na inviolabilidade de integridade física, psíquica e moral, abrangendo a preservação da imagem, da identidade, da autonomia dos valores, ideias e crenças, dos espaços e objetos pessoais. Como bem estabelece o artigo 18: "É dever de todos velar pela dignidade da criança e do adolescente, pondo-os a salvo de qualquer tratamento desumano, violento, aterrorizante, vexatório ou constrangedor” (BRASIL, 1990).

O direito à cultura, preconizado pelo ECA, é garantido pela educação não formal, representada principalmente pelas instituições Centro de Referência Especializado de Assistência Social - CREAS e pelo Centro de Socioeducação - CENSE. Assim sendo, os adolescentes terão a oportunidade de se reintegrarem socialmente.

\section{RESSOCIALIZAÇÃO E MEDIDA SOCIOEDUCATIVA}

Pode-se dizer que a punição sem um fim socioeducativo é inválida. Todo indivíduo que é excluído de seus direitos precisa redimir-se perante a sociedade para que tenha seus direitos retomados, ou seja, para que passe a ser socialmente aceito e tenha seus direitos civis respeitados. Segundo Foucault (1999, p. 146): "Não se pune, portanto, para apagar um crime, mas para transformar um culpado (atual ou virtual); o castigo deve levar em si uma certa técnica corretiva".

A técnica corretiva que Foucault (1999) relata é o que se pode denominar de ressocialização, que consiste num ato necessário para que a ação do adolescente seja repensada, seja responsabilizada e que a punição (castigo) será na verdade uma ação voltada à reflexão.

Ressocialização é a reintegração do menor autor de ato infracional à sociedade para que ele volte a conviver em paz com os outros indivíduos, não somente aplicando uma medida com o fim de reprimir o adolescente ou a criança infratora, mas de fato reeducá-los a ter princípios, urbanidade e civilidade. As políticas públicas de ressocialização do jovem enfatizam a educação e a profissionalização como ferramentas importantes na construção 


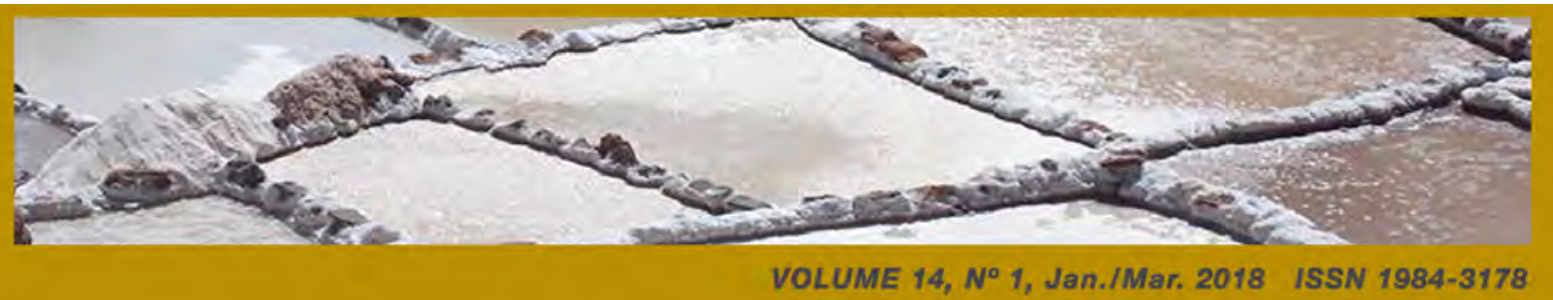

deste novo indivíduo, ao qual devem ser dadas condições plenas de reestruturação psíquica e familiar e de reinserção social, a partir de sua compreensão individualizada e particularizada, a fim de resgatá-lo enquanto ser humano e sujeito em sintonia com o momento histórico.

A medida socioeducativa, conforme propõe o Instituto de Ação Social do Paraná IASP (PARANÁ, 2006), é uma decisão judicial, dedicada somente ao menor autor de ato infracional e objetiva a reintegração deste à sociedade, dando-lhe chance de desenvolver competências para ser e conviver sem infringir a lei. É incontestável, que as medidas socioeducativas constituem-se numa resposta social destinada ao adolescente, entretanto, na sua aplicação deve prevalecer o caráter sociopedagógico, que não visa meramente à retribuição ou punição pelo ato cometido, mas sim o proporcionar um novo projeto de vida que o liberte do submundo do crime e da marginalização, através de sua reinserção social, familiar e comunitária, que lhe garante a alimentação, educação, saúde, cultura, lazer, profissão, aliados à realização de atitudes e ações beneficiárias do Estado, sociedade e família em proveito da transformação da realidade do autor de ato infracional. A medida socioeducativa é um ato de cidadania, haja visto que proporciona condições cidadãs de reabilitação e ressocialização.

Assim, a punição age como uma forma de transformar o culpado em um agente responsabilizado e, portanto, sua ação (cumprimento da medida socioeducativa) terá um fim aceito socialmente. Portanto, a ressocialização tem uma finalidade muito mais complexa, tanto que seus efeitos trazem benefício à sociedade, ao sujeito autor de ato infracional e até à própria família, que é participante ativa na responsabilidade pelo adolescente.

A punição que era realizada no período anterior ao ECA não teve efeitos concretos perante o judiciário. A partir disso, por força de alguns decretos junto ao governo federal, a sociedade e o judiciário foram forçados a repensar as punições e amadurecer a forma de pensar mecanismos eficientes, agora com a finalidade de ressocializar e não apenas punir o infrator. Para Foucault (1999, p. 28, grifo do autor):

Analisar antes os "sistemas punitivos concretos" estudá-los como fenômenos sociais que não podem ser explicados unicamente pela armadura jurídica da sociedade nem por suas opções éticas fundamentais; recolocá-los em seu 
campo de funcionamento onde a sanção dos crimes não é o único elemento; mostrar que as medidas punitivas não são simplesmente mecanismos "negativos" que permitem reprimir, impedir, excluir, suprimir; mas que elas estão ligadas a toda uma série de efeitos positivos e úteis que elas têm por encargo sustentar (e nesse sentido, se os castigos legais são feitos para sancionar as infrações, pode-se dizer que a definição das infrações e sua repressão são feitas em compensação para manter os mecanismos punitivos e suas funções).

O adolescente é um ser em desenvolvimento, portanto, necessita de orientação e direção para que suas ações sejam positivas e bem aceitas socialmente. A arte colabora com esse processo, evidenciando a necessidade de reflexão e materialização das expectativas desses jovens operando pois, como um instrumento humanizador e, assim sendo, seu processo é mais importante que o resultado.

\section{ARTE NA SOCIOEDUCAÇÃO}

A arte-educação promove o desenvolvimento de sensibilidade, imaginação, criatividade do ser humano, proporcionando crescimento emocional, intelectual e estético do sujeito, tal como afirma Mosquera (1976). Desta maneira, há a possibilidade de a arte despertar o sentimento de integração, colocando o interno como membro da sociedade e minimizando as barreiras para a participação social do sujeito. Segundo Fischer (2007, p. 27):

\footnotetext{
A arte - como meio de identificação do homem com a natureza, com os outros homens e com o mundo, como meio de fazer o homem sentir e conviver com os demais, com tudo o que é e com que está para ser - está fadada a crescer na mesma medida em que cresce o homem.
}

Assim, a arte rompe com a represália, que normalmente ocorre, quando o menor retorna à liberdade e mesmo enquanto ainda está privado desta. No decorrer do processo artístico, também podem ser evocados reflexões éticas e morais. Ao falar sobre a moral na arte, Nunes (1999, p. 40) afirma: 


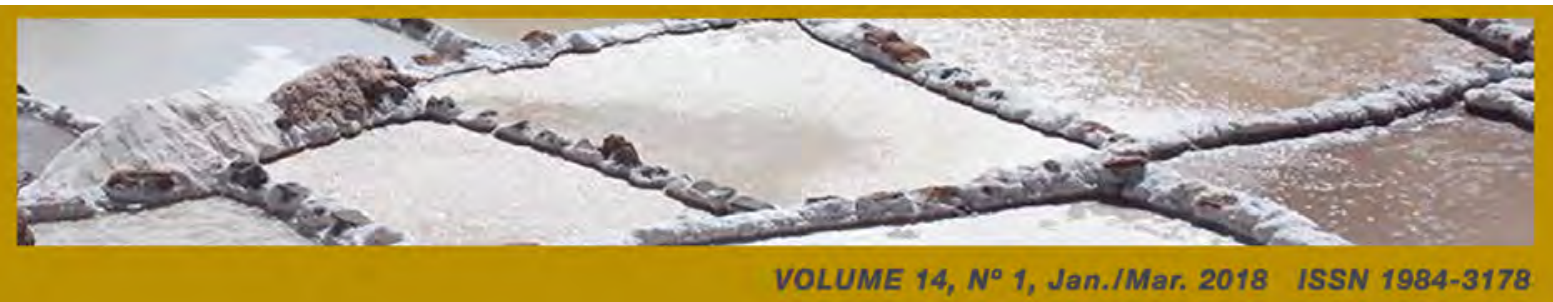

Sem conduzir diretamente nem ao compromisso moral nem à atividade de caráter social ou político, é uma forma de apelo, de solicitação, capaz de despertar a consciência moral para a descoberta dos valores éticos, inclusive os sociais e políticos. [...] Em suma, é revelando as possibilidades da consciência moral e não adotando uma moral, que a arte cumpre sua finalidade ética.

Sendo assim, a arte não tem um caráter julgador, ao contrário, ela permite que seja expressa a ideia do potencial artista. A arte é receptiva aos contrastes da vida. Essa liberdade de expressão se torna essencial para que não haja ostracismo, além de permitir denunciar todos os problemas que o sujeito sofre, sejam problemas sociais ou problemas internos. Por meio da arte, podem ser questionados aspectos da vida que o menor infrator tem vivenciado e assim the oportunizar condições para sua expressão de mundo. Neste contexto de vivências artísticas o jovem pode conquistar uma vida mais significativa. Fischer (2007, p. 175) afirma que:

Para se ser artista, é necessário colher, controlar e transformar a experiência em memória, a memória em expressão, a matéria em forma. A emoção para um artista não é tudo [...] A paixão que consome o diletante, serve ao verdadeiro artista; o artista não é maltratado pela besta: doma-a.

Ou seja, ter experiência artística permite ao indivíduo controlar a possível revolta e converter suas experiências em obras, que exprimam toda a sua vida para os outros e para si mesmo. Neste processo ocorre integração e acolhimento

\section{METODOLOGIA}

Para desenvolvimento desta pesquisa, foram utilizadas referências bibliográficas que fundamentam teoricamente as conclusões. Buscando embasamento teórico a partir dos pensamentos de críticos e filósofos como Michel Foucault, Ernst Fischer e Benedito Nunes. Analisou-se o fenômeno social da ressocialização buscando investigar qual o potencial de contribuição do fazer artístico nesta ação. Amparados em análises da legislação vigente, averiguamos os aspectos referentes à Constituição Federal para, assim, verificar quais 
possibilidades e proposições a lei apresenta para o contexto desta pesquisa.

Coletamos dados de estrutura, funcionamento e atuação da instituição focalizada nesta pesquisa, o CREAS II do município de Cascavel-PR. Investigamos a existência de projetos ou ações voltadas para o desenvolvimento artístico dos adolescentes nesta instituição e propomos uma pesquisa-ação.

Com base na metodologia de pesquisa-ação, buscamos identificar a efetividade da aplicação de artes plásticas, mais precisamente a escultura em argila, como modo de ressocialização do adolescente em conflito com a lei, visando o protagonismo destes jovens junto à sociedade e possibilitando-lhes uma reflexão sobre seus atos. Segundo Baldissera (2001, p.6)

Uma pesquisa pode ser qualificada de pesquisa-ação quando houver realmente uma ação por parte das pessoas implicadas no processo investigativo, visto partir de um projeto de ação social ou da solução de problemas coletivos e estar centrada no agir participativo e na ideologia de ação coletiva.

A pesquisa-ação proporciona uma troca de saberes entre os participantes e pesquisadores, além de enriquecimento dos conhecimentos de todos os envolvidos no processo (NUNES; INFANTE, 1996). Para Thiollent (1985) deve haver uma direta interação entre os pesquisadores e envolvidos na pesquisa. Este tipo de pesquisa tem a intenção de aumentar o conhecimento dos pesquisadores e o conhecimento ou nível de consciência das pessoas participantes.

Na pesquisa-ação ocorre uma dialética: primeiramente se estuda o assunto, propõe-se uma ação interventiva na realidade estudada e analisa-se o resultado desta ação. A investigação ocorre antes, durante e depois da ação aplicada com os adolescentes. Sendo assim, os dados gerados a partir de debates junto aos adolescentes que frequentam o espaço CREAS II para cumprimento de medida socioeducativa. Estes dados foram fundamentais para a reflexão após ter sido aplicada pelos pesquisadores, a atividade de escultura em argila com o tema proposto para as oficinas. 


\section{RESULTADOS}

O CREAS II - Centro de Referência Especializado de Assistência Social localizado na Rua Luciano Correia Siqueira, 224 - Bairro Coqueiral, na cidade de Cascavel - PR, é responsável pelo Serviço de Proteção Social para adolescentes em cumprimento de medida socioeducativa de Liberdade Assistida (LA) e de Prestação de Serviços à Comunidade (PSC). O serviço tem por finalidade prover atenção socioassistencial e acompanhamento a adolescentes e jovens em cumprimento de medidas socioeducativas em meio aberto, que são determinadas judicialmente.

O Serviço de Proteção a Adolescentes em Cumprimento de Medida Socioeducativa em Meio Aberto atende adolescentes de 12 a 18 anos incompletos, ou jovens de 18 a 21 anos, em cumprimento de Medida Socioeducativa de LA e de PSC, aplicada pelo juiz da Infância e da Juventude.

O CREAS II propõe oficinas para trabalhar as artes junto aos adolescentes, a exemplo da oficina de rima, que trabalha a arte literária.

Com o intuito de averiguar a aplicabilidade dos conceitos abordados na teoria, ou seja, como a produção artística pode contribuir para a ressocialização de adolescentes em conflito com a lei, os pesquisadores aplicaram uma oficina com o público em foco nesta pesquisa. Ao apresentar o tema que foi previamente definido por uma equipe técnica psicossocial - que ao fazer o atendimento deste público especifico, tem identificado o problema da falta de perspectiva para o futuro, sendo este o tema principal - e ao debater o assunto com os participantes, conduzimos a reflexão e a materialização das expectativas que foram transformados em esculturas. Após a realização de uma pesquisa de imagens na sala de informática, foi possível ajudar os adolescentes na escolha da melhor forma de materializar seus ideais.

A instituição CREAS II conta com uma equipe psicossocial que, em conjunto com o Poder Judiciário, aplica as medidas socioeducativas aos adolescentes em conflito com a lei. A instituição forneceu abertura para que o trabalho aqui relatado fosse executado. As oficinas aplicadas passaram pela equipe pedagógica e sendo discutida a finalidade da aplicação, 


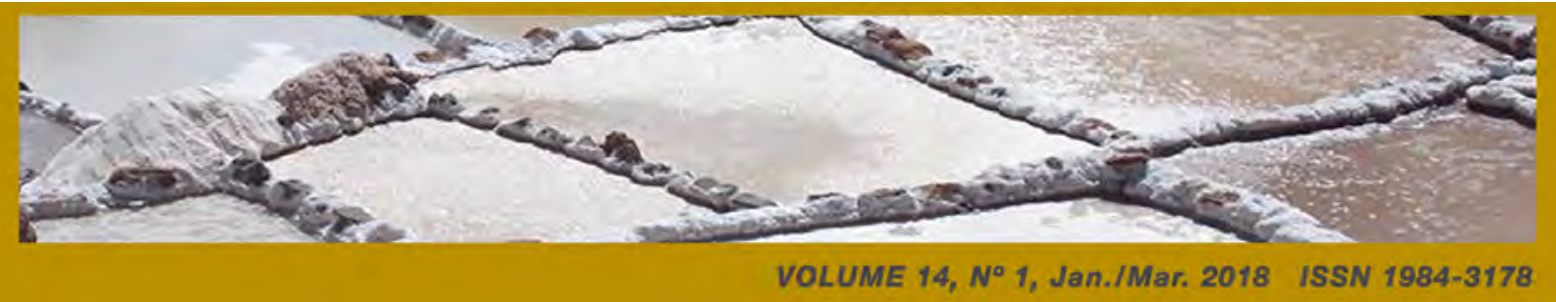

chegou-se ao consenso de que os adolescentes não têm muitas expectativas, contando com a hipótese de que a arte poderia trazer uma reflexão aos jovens e uma futura mudança de atitude. Após definido o tema para a aplicação das oficinas, foram definidas as salas a serem usadas e o material a ser aplicado.

As oficinas foram projetadas para a participação de uma média de três adolescentes, os quais chegavam à instituição por volta das treze horas ou às oito horas da manhã, e permaneciam junto à oficina, em média, por três horas-aula, com um intervalo de cerca de quinze minutos para o lanche.

O questionário utilizado para instigar os adolescentes foi composto das seguintes indagações: Onde você quer estar daqui a cinco anos? E como você quer estar? Onde você quer estar daqui a um ano e como? O que você espera para o futuro? O que você quer fazer no futuro? Como você quer alcançar seus objetivos?

Após a apresentação do projeto, na roda de conversa inicial foram feitas perguntas do questionário para instigar a reflexão. Em seguida, os adolescentes fizeram pesquisas de imagens sobre o que eles queriam representar sobre seu futuro, para ajudar na materialização das esculturas em argila.

Dirigindo os adolescentes até o local previamente preparado para a execução dos trabalhos, foram distribuídos avental e luvas, ferramentas para esculpir, jornal para forrar a mesa e foi dividida a argila. Assim, todos puderam iniciar seus respectivos trabalhos com a purificação da argila e subsequente modelagem.

Ao concluírem os trabalhos artísticos, foi feita a limpeza do local utilizado, fazendo o armazenamento para secagem das obras. Por último, realizou-se um debate sobre como foi para aqueles jovens poder materializar seus sonhos e como eles esperam alcançar seus objetivos.

No mês de agosto de 2016, foi feita uma exposição dos trabalhos executados pelos adolescentes, sendo usado o espaço de exposições do Teatro Municipal Sefrin Filho no município de Cascavel/PR, e, posteriormente, outros locais para concluir a aplicação.

A cada dia de oficina obteve-se um resultado diferente. Pelo fato do perfil de cada 
adolescente ser único, o resultado, ou seja, a fala de cada adolescente foi variada. Porém, pode-se perceber que estes jovens não apresentam perspectiva para o futuro, o que leva à reflexão sobre quais políticas públicas poderão ser mais reforçadas para que este quadro mude.

Nesta parte, cada adolescente será identificado por letras, em ordem alfabética conforme sua participação nas oficinas. No total, o projeto foi aplicado a 14 adolescentes.

No primeiro dia de oficina participaram três adolescentes com idades entre 13 e 17 anos. O tema foi "A expectativa de futuro". Assim, foram feitas as seguintes indagações: "Como vocês se imaginam daqui a cinco anos? Onde vocês querem estar? Fazendo o que?".

Abaixo se relatam as reações dos adolescentes que participaram no primeiro dia da oficina.

Em diálogo com o Adolescente A, com idade de 15 anos, se percebeu que ele tem pouca expectativa em relação ao futuro. A princípio não demonstrou interesse, mas prosseguiu na atividade. Após apresentada a proposta e feitas as perguntas, ele disse que nunca havia pensado sobre o futuro. Ao ser questionado sobre onde ele quer estar daqui a um ano, ele também não soube responder. Após sua pesquisa e definiu-se uma imagem para base, esta foi impressa para ajudá-lo na confecção do trabalho.

Durante a execução do trabalho, demonstrou-se bastante interessado e pediu para fazer mais de uma escultura. Seu objetivo é ter um carro e, ao materializá-lo, projetou todos os detalhes, como os faróis, detalhes das rodas, retrovisor, entre outros. No debate, após a oficina, disse ter gostado de trabalhar com a argila e que não conhecia a técnica. Quando uma estagiária se aproximou dele, perguntou se ela gostou do seu trabalho e relatou que os visitantes da exposição iriam gostar.

Durante o diálogo inicial o Adolescente $\mathrm{B}$, com idade de 17 anos, teve pouco interesse. Ao ser questionado sobre o futuro, não quis responder nada. Porém, durante a execução, foi o que mais se dedicou ao trabalho, cuidando de todos os detalhes. Escolheu fazer uma escultura de cachorro porque disse que quer um e que era mais fácil para fazer. Mas durante o diálogo relatou que quer fazer um curso de mecânico de motos e quer ter sua própria moto; disse que faria uma folha de maconha também, mas ao ser perguntado sobre se 


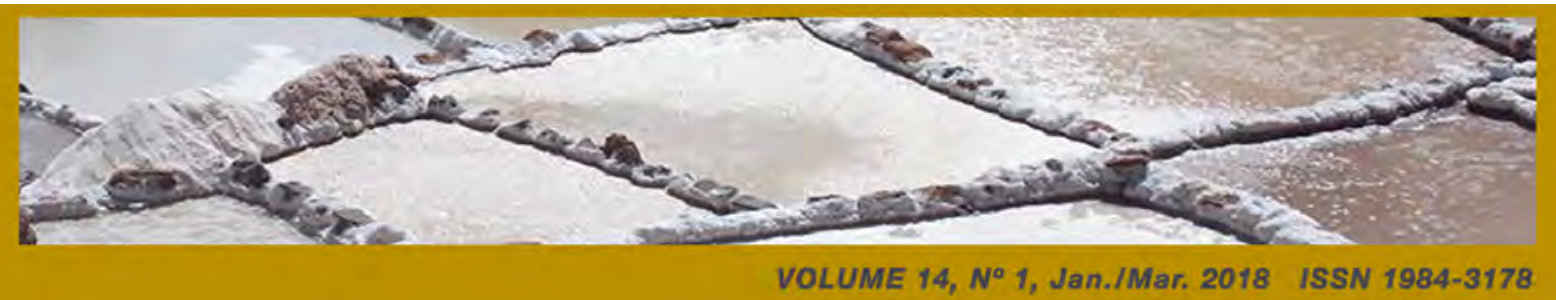

era isso mesmo que ele esperava para o futuro, o adolescente respondeu negativamente, sinalizando que era algo errado e que tinha consciência disso.

Segundo relatos de educadores e estagiários da instituição que aplicaram outras oficinas para este jovem, ele tem muita dificuldade e indisposição para fazer as atividades propostas, fala pouco, só responde ao que perguntam, baixa o boné sobre rosto e não se comunica com ninguém durante as oficinas. No entanto, durante a oficina de artes ele conversou bastante, relatou que gostou da oficina, que não havia trabalhado com argila antes e que as pessoas que visitariam a exposição iriam apreciar. Ao observar os relatos dos educadores, pode-se perceber o quanto a arte pode favorecer a expressão deste jovem. Além de estimular o diálogo e sua interação social.

O Adolescente C, com 13 anos de idade demonstrou interesse nas atividades. Mas, talvez pela idade que apresenta, sua expectativa para o futuro ainda é bem vaga. Seu único assunto foi videogame. Fez a representação de um videogame de última geração, rapidamente, sem muitos detalhes, para poder ficar brincando com a argila. Sua fala enfatiza a referência que tem do irmão mais velho. Relatou por diversas vezes que jogava com seu irmão e que os dois são bem ligados. Disse não ter trabalhado com argila ainda, que gostou e que não sabia se os visitantes da exposição entenderiam que sua representação era um videogame.

No segundo dia de aplicação, participaram três adolescentes com idade entre 16 e 18 anos. Seguem as descrições das experiências vivenciadas pelos adolescentes que participaram no segundo dia da oficina:

O Adolescente D, com 18 anos teve boa participação na oficina. Relatou que tem interesse em fazer um curso de mecânica de motor a diesel e que quer trabalhar com máquinas de grande porte, mas esse é um desejo para um futuro distante, pois relatou que no momento precisa arrumar um emprego e terminar sua casa. A peça confeccionada foi uma turbina de motor. Ele foi bem detalhista em seu trabalho. Apesar de suas expectativas serem em longo prazo, tem a intenção de fazer algo para o futuro. Relatou não ter trabalhado com argila na escola e que parou de estudar por um tempo.

Já a Adolescente E, com idade de 16 anos teve bastante interesse na atividade. Relatou que quer ser professora de dança hip hop. Sabe que precisa de uma graduação para alcançar 
seus objetivos, mas relatou não estar estudando no momento. Fez uma dançarina de hip hop. Seu trabalho foi rico em detalhes, se preocupou em representar um passo de dança bem usado. Quando questionada sobre seu futuro, a adolescente relatou que voltará a estudar, que quer "correr atrás de seus interesses", que não havia trabalhado com argila antes e que gostou da experiência. Também relatou que gostaria que os governantes dessem mais oportunidades de emprego para que ela pudesse atingir seus objetivos.

O Adolescente F, com 17 anos de idade é um jovem de classe média, possivelmente com mais instrução do que os demais. Relatou que será desenhista, fará estampas de camisetas, e que terá sua própria marca. Segundo ele, já expôs seus desenhos, junto com outros colegas. Disse que quer manter seu trabalho após a exposição, pois colocará em sua sala de desenho como a primeira materialização de seus objetivos. Parecendo melhor esclarecido, este jovem tem projetos em curto prazo. Relatou ter apoio dos pais para montar sua marca e disse já ter trabalhado com argila.

No terceiro dia de aplicação, participaram três adolescentes com idade de 17 anos. Seguem os relatos:

O Adolescente G, com 17 anos, se mostrou participativo ao ser questionado sobre onde e como queria estar daqui a cinco anos. Ele disse que queria estar bem financeiramente, mas que não tinha ideia de como fazer para alcançar esta meta. Acrescentou que precisaria de um emprego e que não conseguiu nada ainda, apesar de ter entregado currículos e feito entrevistas. A escultura que ele escolheu fazer foi um carro antigo, disse que quer ter um quando completar 18 anos. Relatou que gostou da atividade e pediu se teria mais atividades como aquela.

Em contrapartida, a Adolescente 8, com 17 anos foi bem resistente no começo, mas participou. Reclamou bastante, pois a reflexão a incomodou. Disse que não pensa no futuro, que quer viver o agora. Não quis compartilhar seus pensamentos, mas foi possível perceber que a reflexão inicial a deixou desconfortável. Também fez uma escultura de um carro antigo, alegando que quer um carro neste estilo. Fez a escultura com bastante detalhes.

O Adolescente $\mathrm{H}$, com 17 anos, fez a escultura de uma folha de maconha. É um adolescente com poucas expectativas e de difícil convívio. Gosta de caçoar dos colegas. 
Relatou gostar de artes e que era a única matéria que gostava na escola. Fez uma placa de argila com traços à mão livre. Relatou gostar de desenhar. Ao ser questionado sobre o que espera para o futuro, reagiu de forma ríspida, disse que não tem futuro e que era isso mesmo. A reflexão o perturbou a tal ponto que ele reagiu com irritação.

No quarto dia de aplicação, participaram 5 adolescentes, cujas experiências são descritas a seguir:

O Adolescente I, com 18 anos participou ativamente reflexivo e decidido sobre seu futuro. Fez uma placa de argila com símbolo de engenharia. Relatou estar no terceiro ano do ensino médio, que está se preparando para o vestibular no curso engenharia mecânica. Também relatou querer sua escultura após exposição. Gostou de trabalhar com argila.

A Adolescente J, com 16 anos: Fez uma placa de argila com símbolo de eterno amor. Durante a reflexão, disse nunca ter pensado no futuro, que não tem expectativa e que não quer se preocupar com isso. Disse que fez o símbolo porque tem uma filha de dez meses. Ficou irritada durante a confecção da placa, por dificuldade em trabalhar com o material, sendo que logo que terminou a obra, abandonou a oficina, antes mesmo do fim. Relatou estar em crise de abstinência, mas que não quer abandonar o uso de entorpecentes. Afirmou que não gostou da oficina de artes. As reflexões sobre o tema bem como a abstinência, perceptivelmente, incomodaram-na muito.

O Adolescente K, com 17 anos, fez uma placa de argila com símbolo de paz. Tinha bastante pressa para ir embora. Gosta de artes e grafismo. A reflexão sobre o que esperava do futuro deixou-o pensativo, mas não quis compartilhar com os demais. Seu trabalho foi bem detalhista.

Também, o Adolescente L, com 17 anos, ficou retraído e calado durante a oficina. Fez o trabalho com muitos detalhes e com paciência. Disse que gosta de artes e que quer seu trabalho para levar para casa. A reflexão o incomodou, pois disse nunca ter pensado nisso e que não sabe o que quer para o futuro. A todas as perguntas ele respondia que não sabia. Sua escultura foi a de uma casa, a partir de um bloco. Disse que isso é o que ele quer ter no futuro, sua própria casa.

Por último, o Adolescente M, com 20 anos, teve disposição para o trabalho. Aparentou 
saber o que quer para futuro, pois deseja fazer engenharia civil e construir sua própria casa. Relatou que mora sozinho e tem um emprego há mais de um ano. Disse que seu próximo projeto de vida é fazer a carteira de habilitação. Em sua escultura, fez uma casa com área externa e uma poltrona, sendo que conseguiu levantar a casa com placas de argila e telhado, mostrando desenvoltura na modelagem de argila.

Ao refletir sobre os quatro dias de oficina, pode-se perceber a diversidade de experiências, de concepções de vida e expectativas futuras dos adolescentes, envolvidos. Estas diferenças podem estar relacionadas com variáveis como idade, classe social, condições financeiras e graus de instrução. Variáveis estas que estão ligadas a expectativas futuras de vida.

Foi possível observar que mais da metade dos adolescentes em cumprimento de medida socioeducativa tem pouca ou nenhuma expectativa para o futuro. O meio social e a cultura têm forte influência na expectativa destes jovens.

Após a execução da pesquisa e a confecção das esculturas, houve o momento de debate sobre o trabalho executado, em que os adolescentes puderam expor suas expectativas e frustrações.

Durante a reflexão após a oficina, quatro adolescentes pediram para que esse tipo de oficina ocorresse mais vezes. Acredita-se que isso tenha acontecido em função da liberdade de expressão que a argila possibilitou a estes jovens, de modo que essa reflexão foi positiva.

Dois dos adolescentes que participaram tiveram dificuldades quanto à execução das obras, agindo de forma mais ríspida e alegando não ter paciência. Um abandonou o trabalho no final da oficina, mas os demais adolescentes conseguiram executar seus trabalhos com a argila tranquilamente. Acredita-se que este comportamento aconteceu em função de a observação feita a partir das questões aplicadas antes da oficina (que deveriam instigar o adolescente a refletir sobre seu futuro) gerou desconforto na maioria dos adolescentes. A reflexão trazida com as perguntas lançadas em roda de conversa inicial mostrou a eles a necessidade de repensar seus atos pelo fato disso refletir em um futuro e que suas ações atuais provocarão reações que serão vistas pela sociedade.

Segundo Vigotski (1999), a arte tem uma função de projetar o futuro, reflete o que se 


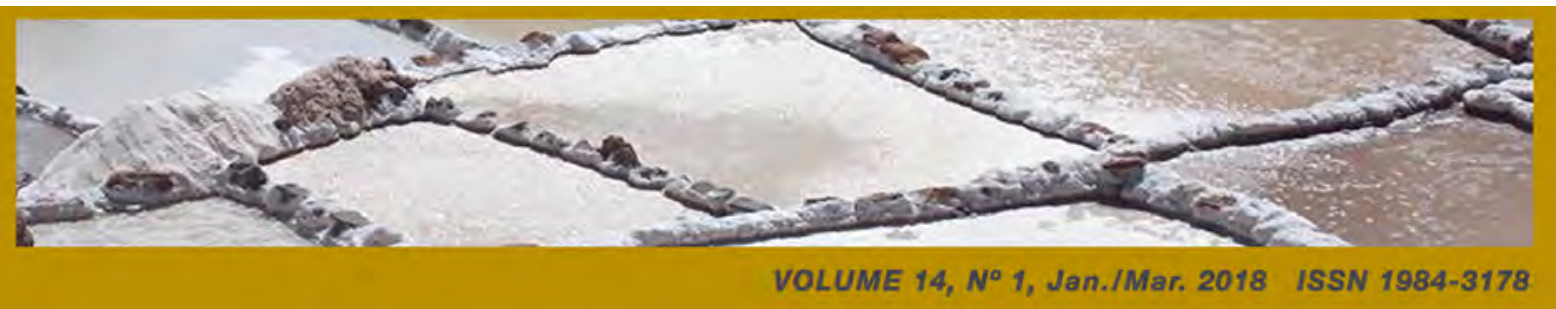

deseja, independentemente de ser alcançado ou não.

\begin{abstract}
"A arte é antes uma organização do nosso comportamento visando o futuro, uma orientação para o futuro, uma exigência que talvez nunca venha a concretizar-se, mas que nos leva e aspira acima de nossa vida o que está por trás dela" (VIGOTSKI, 1999, p. 320).
\end{abstract}

Como já relatado, houve uma diversificação grande de adolescentes envolvidos no projeto. Portanto, os dados aqui compilados foram diversificados. Verificou-se que maioria dos adolescentes gostou de trabalhar com a argila e relatou não ter tido contato com esse material anteriormente.

Ao indagar os adolescentes sobre as opiniões deles em relação aos resultados, muitos agiram de forma positiva, afirmando que se sentiam satisfeitos com o que fizeram, dentro de seus limites e conhecimentos. Apesar de terem ciência que seus trabalhos não são cópias fiéis de sua realidade, a reflexão sobre o que eles esperavam do futuro foi positiva, e ao materializarem seus projetos, foi possível estabelecer uma reflexão sobre o futuro, sobre o caminho até lá e a respeito das ações deles.

A aplicação do presente trabalho foi realizada por meio de exposições no Teatro Municipal Sefrin Filho e em outros espaços da cidade de forma itinerante, nos quais a sociedade, os membros do CREAS II e os jovens puderam expor seus trabalhos e apreciar os resultados da pesquisa e das oficinas.

A exposição intitulou-se "Sonhos e Expectativas". Esta exposição ficou à mostra em mais dois locais, no Shopping JL e no Paço Municipal. A reação do público no local e no dia da abertura foi de satisfação e reflexão sobre o que foi exposto. Nem todos os adolescentes que fizeram os trabalhos puderam estar na abertura, porém visitaram o local posteriormente.

\title{
8 CONSIDERAÇÕES FINAIS
}

Quando são apresentadas as possibilidades de expressão artística para adolescentes, estes desenvolvem habilidades canalizadoras de angústias e sentimentos para uma expressão 


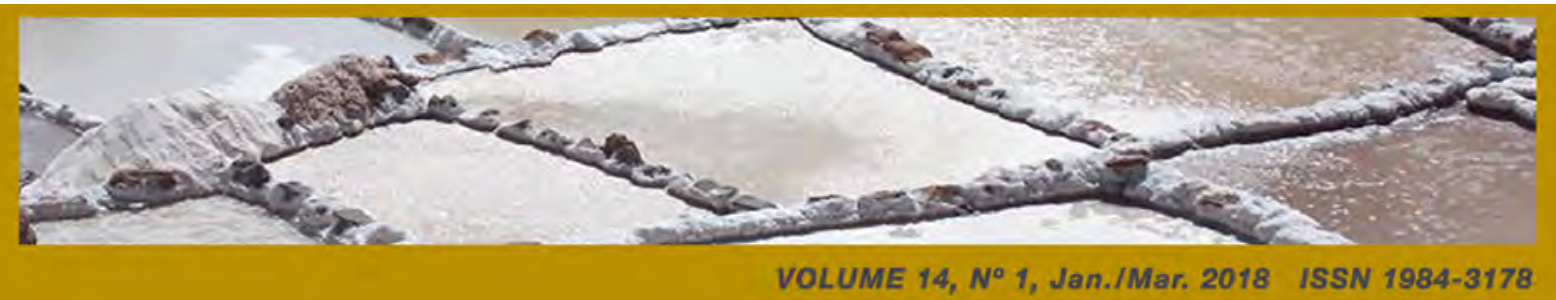

artística em sua definição mais primordial: a interpretação de acontecimentos sociais e emocionais em forma, movimento, imagem e sons

Assim ocorreu nesta oficina de modelagem em argila. Os adolescentes realmente sofrem mudanças comportamentais positivas, como aumento da autoestima e melhoria da capacidade de expressão. Além dos efeitos psicológicos, oficinas de artes podem proporcionar o autoconhecimento e desenvoltura quando reinseridos.

Pode-se concluir que os adolescentes necessitam que os seus responsáveis, os pais, a sociedade e o Estado tenham seus olhos voltados às necessidades individuais destes jovens, pois suas expectativas são de ter uma profissão, ter casa própria e construir família segundo os seus valores, assim como as expectativas futuras de vida de qualquer jovem na mesma faixa etária.

Como foi possível averiguar, o CREAS oferece muitas oficinas, mas não há acompanhamento ou avaliação individual após as oficinas. Uma avaliação individual durante e após a aplicação destes serviços culturais, seria positiva, pois poderia evidenciar a evolução ou estagnação do processo de ressocialização de cada indivíduo e assim, poderia contribuir na reelaboração de projetos sociais como este. Também se mostra essencial o acompanhamento mesmo depois da liberação, visto que estes adolescentes comumente acabam voltando aos crime e infrações ao se verem desamparados (SILVA; OLIVEIRA, 2015). É preciso zelar pelo futuro destes jovens, considerando-os como seres autônomos e suas ações como contingentes.

\section{REFERÊNCIAS}

ABERASTURY, Arminda. O adolescente e o mundo atual. In: Mauricio. Adolescência normal. Porto Alegre: Artes Médicas, 1981. p. 88-90.

; KNOBEL,

BALDISSERA, Adelina. Pesquisa-ação: uma metodologia do "conhecer" e do "agir" coletivo. Sociedade em Debate, Pelotas, v.7, n.2. ago/2001.p.5-25.

BRASIL. Estatuto da Criança e do Adolescente: Lei n 8.069 de 13 de julho de 1990 . Disponível em: <http://www4.planalto.gov.br/legislacao> Acesso em: 10 jun. 2016. 


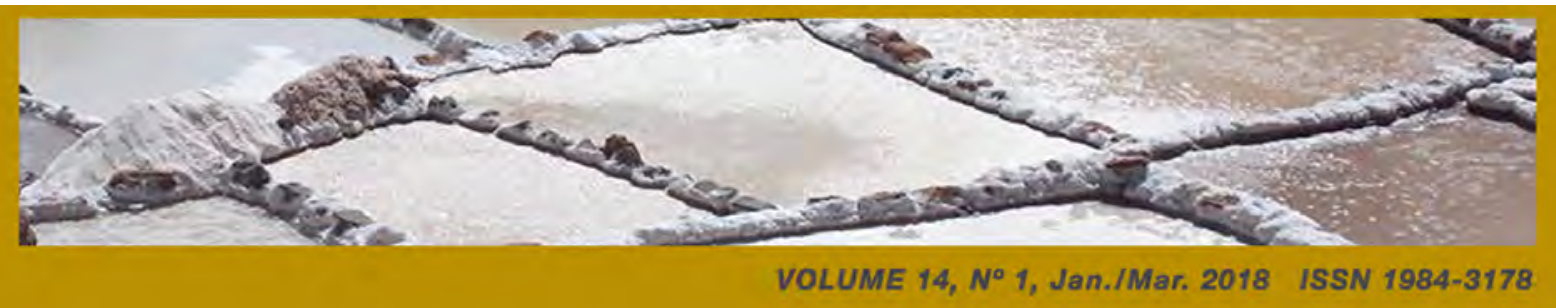

FISCHER, Ernst. A Necessidade da Arte. São Paulo: LTC, 2007.

FOUCAULT, Michel. Vigiar e Punir: nascimento da prisão. Petrópolis, RJ: Vozes, 1999.

GOMBRICH, Ernst Hans. A História da arte. Rio de Janeiro: LTC, 1999.

MOSQUERA, Juan José Mouriño. Psicologia da arte. Porto Alegre: Sulina,1976.

NUNES, Benedito. Introdução à Filosofia da Arte. Rio de Janeiro: São Paulo Editora, 2010.

NUNES, Joaquim Moreira; INFANTE, Maria. Pesquisa Ação: Uma Metodologia de Consultoria. In: ESCOLA POLITÉCNICA DE SAÚDE JOAQUIM VENÂNCIA. (Org.). Formação de Pessoal de Nível Médio para a Saúde: Desafios e Perspectivas. 20. ed. Rio de Janeiro: Editora Fiocruz, 1996. p. 97-114.

PARANÁ. Instituto de Ação Social do Paraná. Cadernos do IASP: Compreendendo o Adolescente. Curitiba: IASP, 2006. 56 p.

SILVA, Enid Rocha Andrade. OLIVEIRA, Raissa Menezes de. O Adolescente em conflito com a Lei e o debate sobre a Redução da Maioridade Penal: esclarecimentos necessários. Brasília: IPEA, 2015.

THIOLlENT, Michel. Metodologia da Pesquisa-Ação. São Paulo: Cortez,1985.

VIGOTSKI, Lev Semenovitch. Psicologia da arte. São Paulo: Martins Fontes, 1999. 